\title{
Prevalence of Rickettsiales in ticks removed from the skin of outdoor workers in North Carolina
}

Sangmi Lee ${ }^{1,3}$, Madhavi L Kakumanu', Loganathan Ponnusamy', Meagan Vaughn², Sheana Funkhouser², Haley Thornton ${ }^{1}$, Steven R Meshnick ${ }^{2}$ and Charles S Apperson ${ }^{1 *}$

\begin{abstract}
Background: Tick-transmitted rickettsial diseases, such as ehrlichiosis and spotted fever rickettsiosis, are significant sources of morbidity and mortality in the southern United States. Because of their exposure in tick-infested woodlands, outdoor workers experience an increased risk of infection with tick-borne pathogens. As part of a double blind randomized-controlled field trial of the effectiveness of permethrin-treated clothing in preventing tick bites, we identified tick species removed from the skin of outdoor workers in North Carolina and tested the ticks for Rickettsiales pathogens.
\end{abstract}

Methods: Ticks submitted by study participants from April-September 2011 and 2012 were identified to species and life stage, and preliminarily screened for the genus Rickettsia by nested PCR targeting the 17-kDa protein gene. Rickettsia were further identified to species by PCR amplification of 23S-5S intergenic spacer (IGS) fragments combined with reverse line blot hybridization with species-specific probes and through cloning and nucleotide sequence analysis of 23S-5S amplicons. Ticks were examined for Ehrlichia and Anaplasma by nested PCR directed at the gltA, antigen-expressing gene containing a variable number of tandem repeats, 16S rRNA, and groESL genes.

Results: The lone star tick (Amblyomma americanum) accounted for 95.0 and 92.9\% of ticks submitted in 2011 $(n=423)$ and $2012(n=451)$, respectively. Specimens of American dog tick (Dermacentor variabilis), Gulf Coast tick (Amblyomma maculatum) and black-legged tick (Ixodes scapularis) were also identified. In both years of our study, $60.9 \%$ of ticks tested positive for 17-kDa. "Candidatus Rickettsia amblyommii", identified in all four tick species, accounted for $90.2 \%$ (416/461) of the 23S-5S-positive samples and 52.9\% (416/787) of all samples tested. Nucleotide sequence analysis of Rickettsia-specific 23S-5S IGS, ompA and gltA gene fragments indicated that ticks, principally A. americanum, contained novel species of Rickettsia. Other Rickettsiales, including Ehrlichia ewingii, E. chaffeensis, Ehrlichia sp. (Panola Mountain), and Anaplasma phagocytophilum, were infrequently identified, principally in A. americanum.

Conclusions: We conclude that in North Carolina, the most common rickettsial exposure is to R. amblyommii carried by $A$. americanum. Other Rickettsiales bacteria, including novel species of Rickettsia, were less frequently detected in A. americanum but are relevant to public health nevertheless.

Keywords: Ticks, Rickettsiales pathogens, Rickettsia, Ehrlichia, Reverse line blot hybridization

\footnotetext{
* Correspondence: apperson@ncsu.edu

'Department of Entomology, North Carolina State University, Campus Box

7647, Raleigh, NC 27695-7647, USA

Full list of author information is available at the end of the article
} 


\section{Background}

Tick-transmitted rickettsial diseases are a significant source of morbidity and mortality globally [1,2]. In the United States, spotted fever rickettsioses (SFR) and ehrlichioses are frequently reported causes of tick-borne rickettsial illnesses [3]. Rocky Mountain spotted fever (RMSF) is the most significant SFR, because it is a potentially fatal disease [1]. Cases of SFR (including RMSF) have escalated in recent years [4]. In 2011, a larger number of cases were reported to the CDC than in any year since 1920 [3]. Of 43 states reporting SFR cases, six states in the midAtlantic and south central regions (Arkansas, Missouri, North Carolina, Oklahoma, Tennessee, and Virginia) reported $70 \%$ of the 2,802 cases reported [3].

The risk of tick-transmitted diseases is an important concern of forestry, military personnel and other professionals engaged in outdoor work, because of their exposure in tick-infested woodlands [5-7]. Avoidance of tick-transmitted illness can be achieved through the use of personal protection methods against tick bites, such as application of chemical repellents to clothing and exposed skin [8]. Because of its persistence and fast action, the synthetic pyrethroid acaricide permethrin is an effective tick repellent when impregnated into clothing [8-10]. Recently permethrin-impregnated clothing was shown to effectively prevent tick bites in a double blind randomized-controlled field trial involving a cohort of outdoor workers in North Carolina [11]. In this study, participants self-reported tick bites and collected ticks from their skin. Here we present a comparative evaluation of the tick species biting study participants and results of molecular analyses of the ticks for selected Rickettsiales bacterial pathogens.

\section{Methods}

\section{Collection and processing of ticks}

Ticks analyzed were collected from the skin of outdoor workers who participated in an evaluation of the effectiveness of clothing impregnated with the repellent/insecticide permethrin in preventing tick bites [11]. Study participants were employed by the North Carolina Division of Forest Resources, the North Carolina Division of Parks and Recreation or the North Carolina Wildlife Resources Commission and worked in central and eastern North Carolina. Ticks, collected by each participant from April to September in 2011 and 2012, were stored in separate vials containing the DNA preservative propylene glycol [12]. Yields of DNA from lone star tick adults preserved in propylene glycol were comparable to ticks preserved in ethanol (unpublished data). Each month, vials were mailed to North Carolina State University, where ticks were processed. Specimens were enumerated by life stage for each species, after which they were stored in ethanol at $-80^{\circ} \mathrm{C}$ until DNA was extracted. Tick nymphs and adults were stored individually but some larvae were grouped into pools of up to five specimens. In 2011, 53 larvae were tested after they were pooled ( 9 and 1 pools containing five and three larvae, respectively, and 5 individual larvae). In 2012, 64 larvae were tested (11, 2 and 1 pools containing five, three and two larvae, respectively, and one individual larva). DNA was extracted from these pools as described below.

\section{Extraction of DNA from tick samples}

Genomic DNA was extracted from individual adults, nymphs and pools of larvae using methods previously described [13]. Crude DNA samples were purified with the Wizard DNA Clean-Up System (Promega, Madison, WI, USA) and the purified DNA was quantified with a NanoDrop (Thermo Scientific, Wilmington, DE, USA). DNA samples were then stored at $-80^{\circ} \mathrm{C}$ for later use.

\section{Molecular detection of Rickettsiales pathogens}

Including DNA extractions from pools of larvae, 787 tick DNA samples (385 and 402 samples in 2011 and 2012, respectively) were prepared and analyzed for pathogens. Genomic DNA was used as template in PCR assays to amplify fragments of gene targets specific for the genus Rickettsia, Ehrlichia chaffeensis, E. ewingii and Anaplasma phagocytophilum. The oligonucleotide primers used are shown in Additional file 1: Table S1 and were synthesized by Integrated DNA Technologies (Coralville, IA, USA). Primary amplification of nested PCR reactions was conducted in a $10 \mu \mathrm{l}$ reaction mixture composed of $1 \mu \mathrm{l}$ of genomic DNA, $0.5 \mu \mathrm{l}$ of forward primer $(10 \mu \mathrm{M}), 0.5 \mu \mathrm{l}$ of reverse primer $(10 \mu \mathrm{M}), 5 \mu \mathrm{l}$ of $2 \times$ AmpliTaq Gold PCR Master Mix (Applied Biosystems, Grand Island, NY, USA) and $3 \mu$ of nuclease-free water (QIAGEN, Valencia, CA, USA). When pooled samples of tick DNA extracts were used (see explanation below), the reaction volume was increased to $20 \mu \mathrm{l}$ and $5 \mu \mathrm{l}$ of the pooled DNA sample was used as template. The nested PCR reaction mix consisted of $1 \mu \mathrm{l}$ of the first PCR product as template DNA, $1 \mu \mathrm{l}$ of forward primer $(10 \mu \mathrm{M}), 1 \mu \mathrm{l}$ of reverse primer $(10 \mu \mathrm{M})$, $10 \mu \mathrm{l}$ of $2 \times$ AmpliTaq Gold PCR Master Mix and $7 \mu \mathrm{l}$ of nuclease-free water. Quality control measures for PCR assays included negative controls (no template DNA) and positive controls (employing DNA from known species of Rickettsia as template) that were amplified in parallel with tick samples in each PCR run. Tick processing was carried out in a non-ventilated PCR enclosure. PCR reactions were prepared in the PCR enclosure or a laminar flow hood. Before they were used, these work areas were thoroughly cleaned with ethanol and exposed to UV light. The PCR conditions for individual rickettsial groups are discussed below.

\section{Genus Rickettsia}

All the tick samples were first screened for genus Rickettsia with primers targeting the Rickettsia genus-specific 17-kDa 
protein gene (Additional file 1: Table S1) [14]. Primary amplification was performed with primers $17 \mathrm{kD} 1 \_F$, 17kD1_R using a thermocycler program consisting of an initial denaturation of $95^{\circ} \mathrm{C}$ for $10 \mathrm{~min} ; 35$ cycles of denaturation at $95^{\circ} \mathrm{C}$ for $30 \mathrm{~s}$, annealing at $47^{\circ} \mathrm{C}$ for $30 \mathrm{~s}$, and extension at $72^{\circ} \mathrm{C}$ for $1 \mathrm{~min}$; and final extension of $72^{\circ} \mathrm{C}$ for $10 \mathrm{~min}$. Primers 17kN1_F and 17kN2_R were used in the nested amplification. The thermocycler conditions were similar to the initial PCR amplification except that the annealing temperature was increased to $50^{\circ} \mathrm{C}$ and the cycles were repeated 30 times. To visualize the nested PCR amplicon, $3 \mu \mathrm{l}$ of each PCR product was electrophoresed in a $1.2 \%$ agarose gel containing ethidium bromide in $0.5 \times$ TAE buffer. Subsequently, 17-kDa-positive samples were further examined with a reverse-line blot (RLB) hybridization assay as described below to identify Rickettsia to species.

\section{Development of a PCR-RLB hybridization assay}

A PCR-RLB hybridization assay was developed to differentiate 10 Rickettsia species (seven spotted fever group [SFG] species, one typhus group [TG] species and, $R$. bellii and $R$. canadensis, representing two ancestral group species), which included confirmed human pathogens ( $R$. conorii, $R$. rickettsii, $R$. parkeri, and $R$. typhi) [15] and a Rickettsia species ("Candidatus R. amblyommii") that has been frequently detected in North Carolina ticks [16-18]. Control DNAs for Rickettsia species were obtained from the Rickettisal Zoonoses Branch, the Centers for Disease Control and Prevention (Atlanta, GA, USA). $R$. conorii and $R$. typhi were included in our study because of their availability, not because we expected these rickettsiae to be detected in the ticks tested.

The assay combined PCR amplification of a $\sim 400 \mathrm{bp}$ fragment of the variable 23S-5S IGS and RLB hybridization procedures as previously published $[19,20]$. Briefly, PCR was conducted using the parameters described by Jado et al. [19] in a $20 \mu \mathrm{l}$ reaction mixture consisting of $1 \mu \mathrm{l}$ of tick DNA extraction, $1 \mu \mathrm{l}$ of primer RCK/23-5-F $(10 \mu \mathrm{M})$, $1 \mu \mathrm{l}$ of primer RCK/23-5-F $(10 \mu \mathrm{M}), 10 \mu \mathrm{l}$ of AmpliTaq Gold PCR Master Mix, and $7 \mu \mathrm{l}$ of nuclease-free water (Additional file 1: Table S2) [19]. The primers used in this reaction were biotin-modified at the $5^{\prime}$ end and were purchased from Invitrogen (Grand Island, NY, USA). One microliter of PCR products was visualized in a $1.2 \%$ agarose gel, containing ethidium bromide. Those samples displaying a band were diluted by mixing $10 \mu \mathrm{l}$ of the PCR product and $180 \mu \mathrm{l}$ of $2 \times \mathrm{SSPE} / 0.1 \%$ SDS solution, and used in RLB hybridization assays described below.

Probes used in the RLB hybridization are shown in Additional file 1: Table S2. Out of 16 probes, seven were previously published by Jado et al. [19], and the remaining nine were designed for our study. In designing probes, we retrieved DNA sequences of different Rickettsia species from the National Center for Biotechnology Information (NCBI, http://www.ncbi.nlm.nih.gov/) aligned them with ClustalW2 (http://www.ebi.ac.uk/Tools/msa/clustalw2/) [21] with the region between primers RCK/23-5-F and RCK/ 23-5-R. Short nucleotide sequences specific to particular Rickettsia species were identified through visual inspection and used as probes in the hybridization. All oligonucleotide probes were synthesized with 5 '-terminal amino group label by Invitrogen. Probes were dissolved in nuclease-free water to $100 \mu \mathrm{M}$ and further diluted to $200 \mu \mathrm{l}$ at 1 and $2 \mu \mathrm{M}$ with $0.5 \mathrm{M} \mathrm{NaHCO}_{3}$ (pH 8.4). For probes whose signal was consistently weak (P-MON3, P-MON4, P-RHIPI and P-RIC), higher concentration dilutions $(4$ and $8 \mu \mathrm{M})$ were also prepared.

The probes were hybridized with PCR products as described previously by Kong and Gilbert [20] with modifications in their protocol. The RLB hybridization temperature was lowered to $52^{\circ} \mathrm{C}$ from $55-60^{\circ} \mathrm{C}$ and stripping solution concentration and temperature were modified to $0.5 \%$ SDS and $60^{\circ} \mathrm{C}$ instead of $1 \%$ SDS and $80^{\circ} \mathrm{C}$, respectively. Bound PCR products were detected by chemiluminescence with a ChemiDot-It ${ }^{\mathrm{TS} 2}$ Imaging System (UVP, Upland, CA, USA) following incubation of the membrane in ECL detection liquid (Amersham, Little Chalfont, Buckinghamshire, United Kingdom). Some cross-hybridization was anticipated because the amino-labeled probes were 17-25 bp in size with some of the probe sequences varying by a single or just a few nucleotides. Consequently, specificity of the probes and optimal RLB hybridization conditions were determined by RLB hybridizations of the probes with control DNAs representing the 10 target Rickettsia species. This RLB hybridization assay was applied to all tick DNA samples that were positive for genus Rickettsia in the $17-\mathrm{kDa}$ nested PCR assay and generated a $~ 400 \mathrm{bp}$ amplicon in the PCR targeting the 23S-5S IGS. In all the RLB hybridizations, control DNA extractions were also included for quality control of the assay.

\section{Cloning and sequence analysis of Rickettsia spp.}

We amplified, cloned and sequenced 23S-5S gene fragments to identify Rickettsia spp. or to verify RLB assay results. Amplicons from some ticks failed to hybridize to any probe (further referred to as unknowns). Generally, these amplicons were detected as faint gel bands in the aforementioned PCR targeting 23S-5S IGS. All the unknown samples were amplified again using a larger amount $(2 \mu \mathrm{l})$ of genomic DNA. Fifteen samples produced visible gel bands of the appropriate size, which were excised, and the DNA was extracted and gel purified using the QIAquick gel extraction kit (catalog no. 28704, QIAGEN). Also, the 23S-5S amplicons of 24 samples hybridized to probes for two Rickettsia species (further referred as co-infected samples). All 24 samples were amplified again with $2 \mu \mathrm{l}$ of genomic DNA and 17 samples that 
produced bright bands of the correct size were excised and purified. Additionally, DNA samples from three ticks identified to be infected with either $R$. parkeri or $R$. montanensis were amplified again with $2 \mu$ l genomic DNA, cloned and sequenced. In summary, a total of 35 samples (15 unknowns, 17 co-infected and 3 samples that were identified as $R$. parkeril $R$. montanenis) were cloned and sequenced. To generate a 23S-5S rRNA clone library for these three sets of samples, purified DNA for each amplicon was inserted into the plasmid vector pGEM-T (Cat. No A3610, pGEM-T Vector System II; Promega) as specified by the manufacturer. White colonies were picked and checked for the presence of the insert by amplifying the clones with universal vector primers M13F (CCC AGTCACGACGTTGTAAAACG) and M13R (AGCGA TAACAATTTCACACAGG). For each tick, up to 5 clones with inserts of the expected length were sequenced and the rickettsial species were identified as described below.

\section{Amplification of Rickettsia ompA and gltA}

To verify identification of unusual or uncommon Rickettsia spp. (such as $R$. monacensis, $R$. conorii, $R$. felis based on 23S-5S sequencing/blast search), we further screened those samples by amplifying and sequencing other gene targets, such as ompA and gltA, using respective Rickettsia-specific primers as shown in Additional file 1: Table S1. The PCR reactions for gltA and ompA genes were conducted in $20 \mu \mathrm{l}$ volumes comprising $10 \mu \mathrm{l}$ of reaction buffer, $1 \mu \mathrm{l}$ each of forward and reverse primers $(10 \mu \mathrm{M})$ with $1-2 \mu \mathrm{l}$ of gDNA template in primary reactions and $1 \mu \mathrm{l}$ of amplicons from primary PCR reaction used as the template for nested PCR reactions. The PCR conditions used for gltA amplification were modified from the protocol of Choi et al. [22] as follows: initial activation at $95^{\circ} \mathrm{C}$ for $10 \mathrm{~min}$, followed by 30 cycles of denaturation at $94^{\circ} \mathrm{C}$ for $30 \mathrm{~s}$, annealing at $57^{\circ} \mathrm{C}$ for $30 \mathrm{~s}$, and extension at $72^{\circ} \mathrm{C}$ for $60 \mathrm{~s}$, and a final extension cycle of $72^{\circ} \mathrm{C}$ for $5 \mathrm{~min}$ (for primary reaction), and $95^{\circ} \mathrm{C}$ for $10 \mathrm{~min}, 30$ cycles of $94^{\circ} \mathrm{C}$ for $30 \mathrm{~s}$, $55^{\circ} \mathrm{C}$ for $30 \mathrm{~s}$, and $72^{\circ} \mathrm{C}$ for $60 \mathrm{~s}$, and a final cycle of $72^{\circ} \mathrm{C}$ for $5 \mathrm{~min}$ (for nested reaction). The PCR conditions used for ompA gene were: initial activation for $10 \mathrm{~min}$ at $95^{\circ} \mathrm{C}$, followed by 30 cycles of $95^{\circ} \mathrm{C}$ for $30 \mathrm{~s}, 52^{\circ} \mathrm{C}$ for $30 \mathrm{~s}$, and $72^{\circ} \mathrm{C}$ for $1.30 \mathrm{~min}$, and a final extension cycle of $72^{\circ} \mathrm{C}$ for $10 \mathrm{~min}$. The same conditions were used both for primary and nested reactions. The ompA and $g l t A$ amplicons were sequenced using the forward primers of the nested PCR reactions (see Additional file 1: Table S1) as described below.

\section{Phylogenetic analyses of Rickettsia sequences}

BLASTN and nucleotide sequence match analysis were used to compare partial nucleotide sequences of 23S-5S IGS clones, ompA and gltA amplicons to those in the GenBank database. Sequences were aligned with the multiple-alignment CLUSTALX software package [23]. Evolutionary distances between sequences of the 23S-5S clones, ompA and gltA amplicons and the respective genes of known Rickettsia species from the NCBI database were calculated (Kimura 2 parameter model) [24] and phylogenetic trees were separately constructed by the neighbor-joining method [25]. Clones from each tick that were $99-100 \%$ identical in nucleotide sequence were exhibited as one clone in constructed trees. Bootstrap analyses [26], consisting of 1,000 iterations with the MEGA 6 software package [27], were performed to evaluate the robustness of tree topologies.

\section{E. chaffeensis, E. ewingii, and A. phagocytophilum}

Pathogen-specific primers and gene targets are shown in Additional file 1: Table S1 [28,29]. Tick nymphs and adults collected in 2011 were individually tested for $E$. chaffeensis, whereas those collected in 2012 were pooled (10 tick DNA samples per pool) before testing. For detection of E. ewingii and A. phagocytophilum, DNA samples were pooled (10 tick DNA samples per pool) before testing in both years to increase sample throughput because we anticipated that few ticks would be infected with these pathogens. For all three pathogens, only those tick DNA samples in positive pools were individually retested.

Nested PCR for E. chaffeensis detection targeted an antigen-expressing gene containing a variable number of tandem repeats (Additional file 1: Table S1) [3]. In the primary amplification for $E$. chaffeensis, the thermocycler was operated under the following program: denaturation at $95^{\circ} \mathrm{C}$ for $10 \mathrm{~min}, 40$ cycles of denaturation $\left(95^{\circ} \mathrm{C}\right.$, $30 \mathrm{~s})$, annealing $\left(55^{\circ} \mathrm{C}, 90 \mathrm{~s}\right)$ and extension $\left(72^{\circ} \mathrm{C}, 90 \mathrm{~s}\right)$, and final extension of $72^{\circ} \mathrm{C}$ for $10 \mathrm{~min}$. In the nested amplification, annealing and extension times were reduced to 30 and $60 \mathrm{~s}$, respectively, and the cycles were repeated 30 times.

For E. ewingii detection, thermocycler conditions in the primary amplification were the same as for E. chaffeensis, except that the annealing temperature and time were changed to $60^{\circ} \mathrm{C}$ and $30 \mathrm{~s}$, respectively, followed by extension at $72^{\circ} \mathrm{C}$ for $1 \mathrm{~min}$. In the nested amplification, these PCR conditions were modified so that the annealing temperature was held at $61^{\circ} \mathrm{C}$ for 45 cycles. Unlike other pathogen detections conducted in this study, $2 \mu \mathrm{l}$ of the primary amplification product was used in the nested PCR amplification for E. ewingii. Nested PCR for A. phagocytophilum targeted heat shock operon (groESL) (Additional file 1: Table S1) and was conducted under conditions previously described [30].

For gltA gene amplification of Panola Mountain Ehrlichia, the PCR conditions in the primary amplification were as follows: denaturing at $95^{\circ} \mathrm{C}$, annealing at $55^{\circ} \mathrm{C}$ for $30 \mathrm{sec}$ and an extension at $72^{\circ} \mathrm{C}$ for $1 \mathrm{~min}$ for 40 cycles followed 
by a final extension at $72^{\circ} \mathrm{C}$ for $5 \mathrm{~min}$. In the nested PCR, the conditions were similar to the primary reaction except that the annealing temperature was increased to $60^{\circ} \mathrm{C}$ [31].

To visualize nested PCR amplicons, 5-10 $\mu \mathrm{l}$ of each PCR product was electrophoresed in a $1.2 \%$ agarose gel containing ethidium bromide in $0.5 x$ TAE buffer.

\section{Sequencing Rickettsiales}

PCR-amplified DNA from the 23S-5S Rickettsia clones and amplicons from nested PCR assays for E. chaffeensis, E. ewingii, and Panola Mountain Ehrlichia, A. phagocytophilum, and Rickettsia ompA and gltA were purified with QIAquick PCR purification kit or, if there were multiplebands, bands of the proper size range were gel-extracted and purified. DNA in the purified PCR products was quantified with a NanoDrop. One primer used in the amplification was employed for sequencing Rickettsia spp. (M13F [23S-5S clones], 190.70p [ompA], RpCS896p [gltA]), E. chaffeensis (FB5C), E. ewingii (EWF1), Ehrlichia sp. (Panola Mountain) (Ehr3CS-214 F), and A. phagocytophilum (HS43), which was performed by Eton BioScience Inc. (Research Triangle Park, NC, USA). Bacterial species from which the DNA sequences originated were identified by comparing the nucleotide sequences with those deposited in GenBank database by means of BLASTN in NCBI [32]. The DNA sequences obtained from the screening for E. ewingii, which targeted the $16 \mathrm{~S}$ ribosomal gene (Additional file 1: Table S1), were additionally analyzed with SeqMatch in the public database of $16 \mathrm{~S}$ ribosomal gene sequences, Ribosomal Database Project (http://rdp.cme.msu.edu/seqmatch/seqmatch_intro.jsp) [33].

\section{GenBank accession numbers}

Nucleotide sequences have been deposited in GenBank with the following accession numbers: antigen-expressing gene containing a variable number of tandem repeats (E. chaffeensis: KJ907737 to KJ907743); groESL (E. ewingii: KJ907744; E. chaffeensis: KJ907745 to KJ907753); $16 \mathrm{~S}$ rRNA (A. phagocytophilum: KJ942183, KJ942185; E. chaffeensis: KJ942184, KJ942186, KJ942210, KJ942230, KJ942242, KJ942243; E. ewingii: KJ942189 to KJ942209, KJ942211, KJ942212, KJ942214 to KJ942218, KJ942222 to KJ942228, KJ942231, KJ942233, KJ942235 to KJ942237, KJ942240, KJ942241; E. ruminantium: KJ942213, KJ942221, KJ942239; Rickettsia montanensis: KJ942234; uncultured bacterium: KJ942187, КJ942188, KJ942219, КJ942220, КJ942232, KJ942238); gltA (Panola Mountain Ehrlichia: KJ796447 to KJ796449; Rickettsia spp.: KP172247 to KP172258); ompA (Rickettsia spp.: KP172259 to KP172268); and 23S-5S IGS (Rickettsia spp.: KJ796403 to KJ796446).

\section{Ethical statement}

The study was approved by the Institutional Review Board of the University of North Carolina, Chapel Hill.

\section{Results}

\section{Comparative abundance of tick species}

In the two-year period of this study (2011-2012), a total of 874 ticks (423 and 451 ticks in 2011 and 2012, respectively) were collected by study participants and submitted for analysis. These ticks consisted of four species; Amblyomma americanum (lone star tick), Amblyomma maculatum (Gulf Coast tick), Dermacentor variabilis (American dog tick) and Ixodes scapularis (black-legged tick) (Figure 1). The majority of ticks were identified as A. americanum in both years (95.0 and $92.9 \%$ in 2011 and 2012, respectively) (Figure 1). All life stages of $A$. americanum ticks were received for identification and testing, with nymphs most frequently identified, accounting for $46.8 \%(188 / 402)$ and $44.9 \%$ (188/419) of $A$. americanum collected in 2011 and 2012, respectively (Figure 1). The other tick species were far less frequently collected than $A$. americanum at frequencies ranging from $0.2 \%$ to $5.9 \%$ each year (Figure 1 ). In contrast to $A$. americanum, only adult ticks were submitted for analysis for these tick species (data not shown). Compared to 2011, D. variabilis increased in 2012 from $2.3 \%(n=10)$ to $5.9 \%(n=27)$ whereas $A$. maculatum declined from $1.7 \%$ $(n=7)$ to $0.2 \%(n=1)$. The percentage of ticks identified as $I$. scapularis did not change appreciably between the two years of the study (Figure 1).

\section{Rickettsia species}

Genus Rickettsia was the predominant putative pathogen identified. Rickettsia species were detected in $60.9 \%$ (479/787) of the DNA samples, including all tick species (Table 1). The infection rate was lower in $2012(52.7 \%$, 212/402) than in $2011(69.4 \%, 267 / 385)$ and this decrease was observed across all tick species except for $D$. variabilis (Table 1). Reduction was most marked among $A$. maculatum (Table 1) and $A$. americanum larvae. Infection rates for larvae declined from $80 \%$ (12 of 15 DNA extractions) in 2011 to $13 \%$ ( 2 of 15 DNA extractions) in 2012.

To identify the species of Rickettsia in 17-kDa-positive DNA samples, we developed a RLB hybridization assay. RLB hybridization patterns of 23S-5S amplicons of 10 control Rickettsia DNAs with four different amino labeled probe concentrations are shown in Figure 2. All control DNAs hybridized with Rickettsia genus probe (GP-RICK) and also hybridized with the intended DNA probes specific for SFG and TG species of Rickettsia.

Of 479 17-kDA-positive samples, 96.2\% (461/479) of the samples were amplified with Rickettsia-specific 23S$5 \mathrm{~S}$ primers. The RLB hybridization was conducted on 461 23S-5S amplicons of which 92.4\% (426/461) hybridized to one or multiple probes and 7.6\% (35/461) exhibited no hybridizations (unknowns). RLB hybridizations identified 24 ticks co-infected with two Rickettsia species, which corresponded to $3.0 \%(24 / 787)$ of the total and 


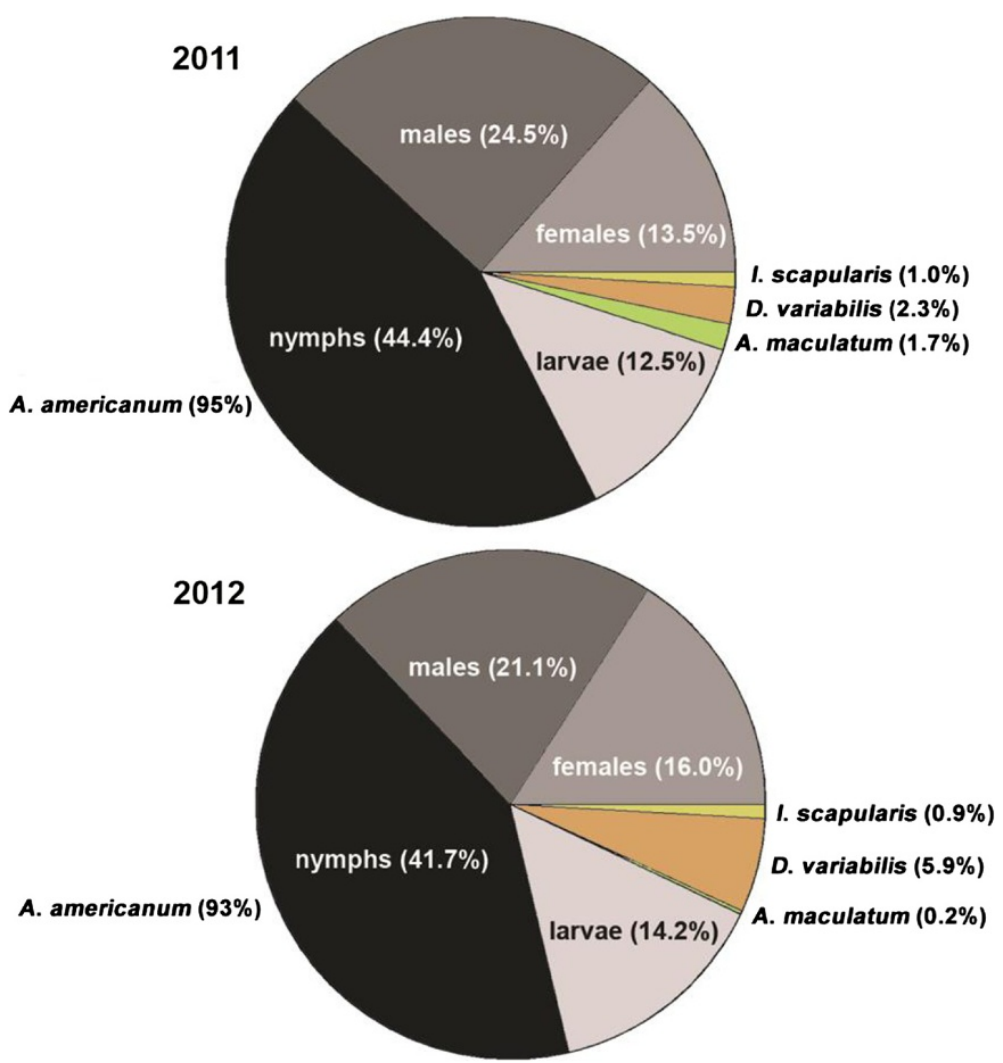

Figure 1 Prevalence of tick species collected from subjects in $2011(n=423)$ and $2012(n=451)$.

Table 1 Infection rates of Rickettsiales bacteria detected in nested PCR assays and identified by sequencing for tick species

\begin{tabular}{|c|c|c|c|c|c|c|}
\hline \multirow[b]{2}{*}{ Bacteria } & \multirow[b]{2}{*}{ Year } & \multicolumn{5}{|c|}{ Number infected (\% infected for each tick species) } \\
\hline & & $\begin{array}{l}\text { A. americanum } \\
(n=821[734])^{a}\end{array}$ & $\begin{array}{l}\text { A. maculatum } \\
(n=8)\end{array}$ & $\begin{array}{l}\text { D. variabilis } \\
(n=37)\end{array}$ & $\begin{array}{l}\text { I.scapularis } \\
(n=8)\end{array}$ & $\begin{array}{l}\text { All species } \\
(n=874[787])^{a}\end{array}$ \\
\hline \multirow[t]{3}{*}{ Rickettsia } & 2011 & $257(70.6)$ & $4(57.1)$ & $2(20.0)$ & $4(100.0)$ & $267(69.4)$ \\
\hline & 2012 & $202(54.6)$ & $-b$ & $8(29.6)$ & $2(50.0)$ & $212(52.7)$ \\
\hline & Total & $459(62.5)$ & $4(50.0)$ & $10(27.0)$ & $6(75.0)$ & $479(60.9)$ \\
\hline \multirow[t]{3}{*}{ E. ewingii } & 2011 & $15(4.1)$ & - & - & - & $15(3.9)$ \\
\hline & 2012 & $37(10.0)$ & - & $3(11.1)$ & - & $40(10.0)$ \\
\hline & Total & $52(7.1)$ & - & $3(8.1)$ & - & $55(7.0)$ \\
\hline \multirow[t]{3}{*}{ E. chaffeensis } & 2011 & $5(1.4)$ & $1(14.3)$ & - & - & $6(1.6)$ \\
\hline & 2012 & $8(2.2)$ & - & - & - & $8(2.0)$ \\
\hline & Total & $13(1.8)$ & $1(12.5)$ & - & - & $14(1.8)$ \\
\hline \multirow[t]{3}{*}{ A. phagocytophilum } & 2011 & - & - & - & - & - \\
\hline & 2012 & $2(0.5)$ & - & - & - & $2(0.5)$ \\
\hline & Total & $2(0.3)$ & - & - & - & $2(0.3)$ \\
\hline
\end{tabular}

${ }^{a}$ Numbers in the brackets represent the number of DNA samples tested for Rickettsiales bacteria. DNA samples were extracted from individual ticks and pools of $A$. americanum larvae. In 2011, 48 larvae ticks were pooled ( 9 and 1 pools containing five and three larvae, respectively). In 2012, 63 ticks were pooled (11, 2 and 1 pools containing five, three and two larvae, respectively). The number of the DNA extractions was used as a denominator to calculate infection rates shown in the table.

${ }^{b}$ The minus symbol indicates that no positive specimens were found among the submitted specimens for this tick species. 
5.2\% (24/461) of the 23S-5S Rickettsia-positive samples. Additionally, 23S-5S amplicons of the unknowns (15 of the 35 samples), co-infected (17 of the 24 samples) and samples that were identified as $R$. parkeri or $R$. montanensis in RLB (3 samples) were successfully cloned and sequenced. "Candidatus R. amblyommii" was the predominant species identified in ticks, accounting for 90.2\% (416/ 461) of the 23S-5S amplified Rickettsia-positive samples and $52.8 \%(416 / 787)$ of all of the ticks tested for pathogens (Table 2). R. amblyommii was detected in all four tick species, but the great majority (99\%; 412/416) of $R$. amblyommii-positive ticks were $A$. americanum (Table 2). The percentage of $R$. amblyommii-infected samples among Rickettsia 17-kDa-positive A. americanum did not change appreciably between 2011 (88.7\%, 228/257) and 2012 (91.1\%, 184/202) (Table 2). In addition to R. amblyommii, RLB hybridization, sequencing and phylogenetic analyses of 23S-5S amplicons revealed that A. americanum harbored a diverse array of Rickettsia species, including $R$. parkeri and some unknown Rickettsia species (labelled Rickettsia sp. A-D in Table 2). Notably $R$. rickettsii was also detected in single $A$. americanum (Table 2). These molecular isolates were $98-100 \%$ homologous to nucleotide sequences for 23S-5S IGS deposited in GenBank. Additionally, 8 amplicons from A. americanum and 1 amplicon from $D$. variabilis hybridized only to SFG rickettsiae probes and could not be further identified. $R$. parkeri was also detected in A. maculatum and $I$. scapularis, and an $R$. monacensis-like species (=Rickettsia sp. C) was identified in three I. scapularis and two $A$. americanum (Table 2).

23S-5S gene fragments from 35 of the 62 (co-infected and unknowns, comprising $26 \mathrm{~A}$. americanum, $5 \mathrm{I}$. scapularis, $1 \mathrm{D}$. variabilis and 3 A. maculatum) samples were successfully cloned and nucleotide sequence analysis of up to 5 clones per tick revealed that 6 of the 35 ticks were co-infected. All co-infections were predominantly detected in $A$. americanum, involving $R$. amblyommii with $R$. parkeri $(n=3)$ or Rickettsia sp. B $(n=2)$, and R. parkeri with Rickettsia sp. A $(n=1)$. These molecular isolates were $98-100 \%$ homologous for $23 \mathrm{~S}-5 \mathrm{~S}$ IGS to nucleotide sequences deposited in GenBank.

Attempts to amplify ompA and gltA gene fragments for ticks containing Rickettsia sp. A that hybridized to the $R$. conorii probe were not successful. However, Rickettsia sp. C ompA and gltA amplicons were $96 \%$ and 99\% homologous, respectively, to $R$. monacensis sequences deposited in GenBank.

\section{Phylogenetic analyses of Rickettsia nucleotide sequences}

A phylogenetic tree was constructed by the neighborjoining method to characterize the relationship between

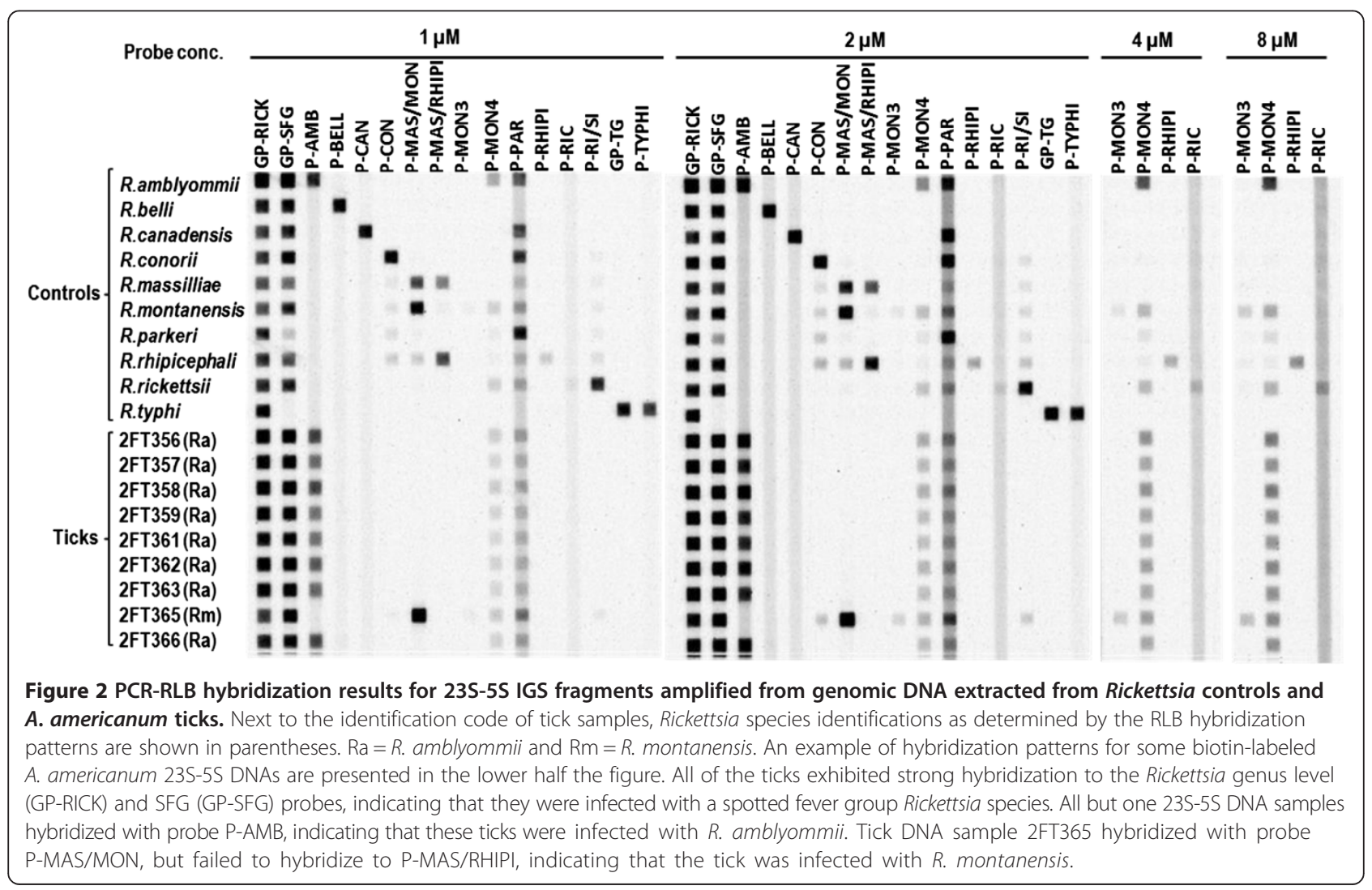


Table 2 Results of PCR-RLB hybridization assays or cloning and sequencing of 23S-5S IGS amplicons for identification of Rickettsia species in 17-kDa-positive ticks

\begin{tabular}{|c|c|c|c|c|c|c|}
\hline \multirow[b]{2}{*}{ Rickettsia species } & \multirow{2}{*}{$\begin{array}{l}\text { Year } \\
\text { collected }\end{array}$} & \multicolumn{5}{|c|}{ Number $\left(\%^{a}\right)$ of samples testing positive for each Rickettsia species within each tick species } \\
\hline & & $\begin{array}{l}\text { A. americanum } \\
{[n=427]^{b}}\end{array}$ & $\begin{array}{l}\text { A. maculatum } \\
{[n=4]}\end{array}$ & $\begin{array}{l}\text { D. variabilis } \\
{[n=4]}\end{array}$ & $\begin{array}{l}\text { I. scapularis } \\
{[n=6]}\end{array}$ & $\begin{array}{l}\text { All tick species } \\
{[n=441]^{f}}\end{array}$ \\
\hline \multirow[t]{3}{*}{ R. amblyommii, } & 2011 & $228(89.8)$ & $2(28.6)$ & $1(50.0)$ & $1(10.0)$ & $232(85.0)$ \\
\hline & 2012 & $184(92.5)$ & $-e$ & - & - & $184(90.2)$ \\
\hline & Total & $412(90.9)$ & $2(28.6)$ & $1(20.0)$ & $1(8.3)$ & $416(87.2)$ \\
\hline \multirow[t]{3}{*}{ R. bellit ${ }^{\mathrm{C}}$} & 2011 & $1(0.4)$ & $1(14.3)$ & - & - & $2(0.7)$ \\
\hline & 2012 & $3(1.5)$ & - & 1 (33.3) & - & $4(1.9)$ \\
\hline & Total & $4(0.9)$ & $1(14.3)$ & $1(20.0)$ & - & $6(1.2)$ \\
\hline \multirow[t]{3}{*}{ R. massiliae ${ }^{c}$} & 2011 & $1(0.4)$ & - & - & - & $1(0.4)$ \\
\hline & 2012 & - & - & - & - & - \\
\hline & Total & $1(0.2)$ & - & - & - & $1(0.2)$ \\
\hline \multirow[t]{3}{*}{ R. montanensis, } & 2011 & - & $1(14.3)$ & - & $1(10.0)$ & $2(0.7)$ \\
\hline & 2012 & - & - & 1 (33.3) & - & $1(0.5)$ \\
\hline & Total & - & $1(14.3)$ & $1(20.0)$ & $1(8.3)$ & $3(0.6)$ \\
\hline \multirow[t]{3}{*}{ R. parkeri, ${ }^{c, d}$} & 2011 & $5(2.0)$ & $2(28.6)$ & - & $3(30.0)$ & $10(3.7)$ \\
\hline & 2012 & $4(2.0)$ & - & - & - & $4(2.0)$ \\
\hline & Total & $9(2.0)$ & $2(28.6)$ & - & $3(25.0)$ & $14(2.9)$ \\
\hline \multirow[t]{3}{*}{ R. rickettsii } & 2011 & - & - & - & - & - \\
\hline & 2012 & $1(0.5)$ & - & - & - & $1(0.5)$ \\
\hline & Total & $1(0.2)$ & - & - & - & $1(0.2)$ \\
\hline \multirow[t]{3}{*}{ Rickettsia sp. $\mathrm{A}^{c, d}$} & 2011 & $7(2.8)$ & - & - & - & $7(2.6)$ \\
\hline & 2012 & $3(1.5)$ & - & 1 (33.3) & - & $4(2.0)$ \\
\hline & Total & $10(2.2)$ & - & $1(20.0)$ & - & $11(2.3)$ \\
\hline \multirow[t]{3}{*}{ Rickettsia sp. $\mathrm{B}^{d}$} & 2011 & - & - & - & - & - \\
\hline & 2012 & $2(1.0)$ & - & - & - & $2(1.0)$ \\
\hline & Total & $2(0.4)$ & - & - & - & $2(0.4)$ \\
\hline \multirow[t]{3}{*}{ Rickettsia sp. $C^{d}$} & 2011 & $2(0.8)$ & - & - & $1(10.0)$ & $3(1.1)$ \\
\hline & 2012 & - & - & - & $2(100)$ & $2(1.0)$ \\
\hline & Total & $2(0.4)$ & - & - & $3(27.3)$ & $5(1.0)$ \\
\hline \multirow[t]{3}{*}{ Rickettsia sp. $D^{c}$} & 2011 & $1(0.4)$ & - & - & - & $1(0.4)$ \\
\hline & 2012 & - & - & - & - & - \\
\hline & Total & $1(0.2)$ & - & - & - & $1(0.2)$ \\
\hline \multirow[t]{3}{*}{ Unknown Rickettsia ${ }^{c, d, h}$} & 2011 & $3(1.2)$ & $1(14.3)$ & - & $4(40.0)$ & $8(3.0)$ \\
\hline & 2012 & $1(0.5)$ & - & - & - & $1(0.5)$ \\
\hline & Total & $4(0.9)$ & $1(14.3)$ & - & $4(33.3)$ & $9(1.9)$ \\
\hline \multirow[t]{3}{*}{ Unknown SFG' } & 2011 & $6(2.4)$ & - & $1(50.0)$ & - & $7(2.6)$ \\
\hline & 2012 & $1(0.5)$ & - & - & - & $1(0.5)$ \\
\hline & Total & $7(1.5)$ & - & $1(20.0)$ & - & $8(1.7)$ \\
\hline
\end{tabular}


Table 2 Results of PCR-RLB hybridization assays or cloning and sequencing of 23S-5S IGS amplicons for identification of Rickettsia species in 17-kDa-positive ticks (Continued)

\begin{tabular}{llllll}
\hline Total infections & 2011 & 254 & 7 & 2 & 273 \\
& 2012 & 199 & 0 & 3 & 2 \\
& Total & 453 & 7 & 5 & 12 \\
\hline
\end{tabular}

${ }^{a}$ Percentage in parenthesis was calculated using the total number of infections detected/identified for Rickettsia in each tick species as the denominator.

${ }^{b}$ Numbers in the brackets represent the total number of 17-kDA-positive samples that were successfully amplified and hybridized in $23 \mathrm{~S}-5 \mathrm{~S}$ PCR-RLB assay from both years of the study for each tick species.

${ }^{C}$ Rickettsia species identified by reverse line blot hybridization. R. massiliae was identified based on hybridization to the P-MAS/MON and P-MAS/RHIPI probes but not to the P-RHIPI probe.

${ }^{d}$ Rickettsia species identified by cloning and sequencing 23S-5S IGS amplicons.

${ }^{e}$ The minus symbol indicates that no positive specimens were found among the tested specimens for this tick species.

f Of $461235-5 S$ positive samples,20 samples were not identified by RLB hybridization or through cloning and sequencing. These samples were not included in the table.

${ }^{9}$ Total number of infections $(n=477)$ exceeds the total number of DNA samples $(n=441)$ because some ticks were infected with more than one Rickettsia species. ${ }^{h}$ Includes Rickettsia sp. E shown in the phylogenetic tree constructed of 23S-5S IGS gene sequences (Figure 3).

Rickettsia 23S-5S IGS nucleotide sequences amplified from ticks and Rickettsia sequences deposited in GenBank (Figure 3). Our results indicate that the ticks (especially A. americanum) contained a diverse array of Rickettsia species. The $23 \mathrm{~S}-5 \mathrm{~S}$ sequences that were $98-100 \%$ homologous to $R$. amblyommii, $R$. parkeri, $R$. rickettsii, and $R$. montanensis from BLASTN were grouped with the respective Rickettsia spp. from GenBank. Rickettsial species identified as Rickettsia sp. A and B were closely homologous to $R$. conorii and $R$. felis, respectively, in the phylogenetic tree. Sequences for Rickettsia sp. C that showed 98\% similarity to $R$. monacensis in BLASTN were placed close to R. monacensis but clustered as a separate branch, suggesting the possibility of a new species or strain. Also the sequences for Rickettsia sp. E that had $87 \%$ similarity with $R$. felis in BLASTN search were branched independently and clustered closer to $R$. bellii, strongly supporting the presence of a novel Rickettsia species.

Phylogenetic trees constructed from Rickettsia ompA and gltA sequences from GenBank are shown in Additional file 2: Figures S1 and S2. Rickettsia spp. previously identified as $R$. parkeri and R. amblyommii (Figure 3) clustered with and were $99-100 \%$ homologous to their respective GenBank ompA and gltA sequences. Rickettsia sp. C sequences clustered close to but as a separate group from $R$. monacensis, supporting the 23S-5S phylogenetic results that showed Rickettsia sp. C to be a putative novel species. Rickettsia sp. E, detected in an I. scapularis female, was grouped with Rickettsia sp. C ompA sequences (Additional file 2: Figure S1) but for gltA, Rickettsia sp. E clustered near R. cooleyi (Additional file 2: Figure S2).

\section{Ehrlichia ewingii}

E. ewingii was the second most frequently identified pathogen in the ticks tested ( $n=55,7.0 \%)$ (Table 1). This pathogen was detected in A. americanum $(n=52,7.1 \%)$ and D. variabilis ( $n=3,8.1 \%$ ) (Table 1). In 2011, 3.9\% of the ticks $(n=15)$ were infected with $E$. ewingii whereas the prevalence markedly increased to $10.0 \%(n=40)$ in
2012 (Tables 1). The increase in prevalence was most pronounced among D. variabilis ( $0 \%$ in 2011 vs. $11.1 \%$ in 2012) (Table 1).

In the course of screening for E. ewingii, sequencing of PCR amplicons revealed that some amplicons were highly homologous to non-E. ewingii bacteria such as Acidobacteria $(n=6)$, E. chaffeensis $(n=8)$, E. ruminantium $(n=3)$, A. phagocytophilum $(n=2)$, and $R$. montanensis $(n=1)$. These ticks were considered to be negative for $E$. ewingii and positive for the other pathogens. To confirm detection of E. ruminantium, a nested PCR assay targeting the citrate synthase gene ( $g l t \mathrm{~A})$ (Additional file 1: Table S1) was carried out for the three A. americanum ticks that tested positive for this agent. Sequencing of gltA PCR amplicons showed that these ticks were infected with an Ehrlichia sp. that was $99-100 \%$ homologous to the Panola Mountain Ehrlichia.

\section{Ehrlichia chaffeensis and Anaplasma phagocytophilum}

A total of $1.8 \%$ of the ticks $(n=14)$ was found to be positive for $E$. chaffeensis by nested PCR assays targeting this pathogen and sequencing of amplicons obtained in the course of screening for A. phagocytophilum and E. ewingii (Table 1). The prevalence was similar in $2011(n=6,1.6 \%)$ and $2012(n=8,2.0 \%)$ (Table 1). A majority of the ticks infected with $E$. chaffeensis were $A$. americanum (adults and nymphs) with the exception of one adult $A$. maculatum tick collected in 2011 (Table 1).

Ticks infected with $A$. phagocytophilum were rarely detected with the infection rate of $0.3 \%(n=2)$ (Tables 1$)$. All the ticks positive for $A$. phagocytophilum were identified through sequencing amplicons attained in the course of screening A. americanum for E. ewingii in 2012 (Table 1).

Rickettsia-Ehrlichia and Rickettsia-Anaplasma co-infections Our nested PCR results revealed that 5.3\% (42/787) of the ticks were positive for multiple Rickettsiales pathogens and such co-infections predominantly included Rickettsia species. Among the ticks collected in 2011, a total of 16 


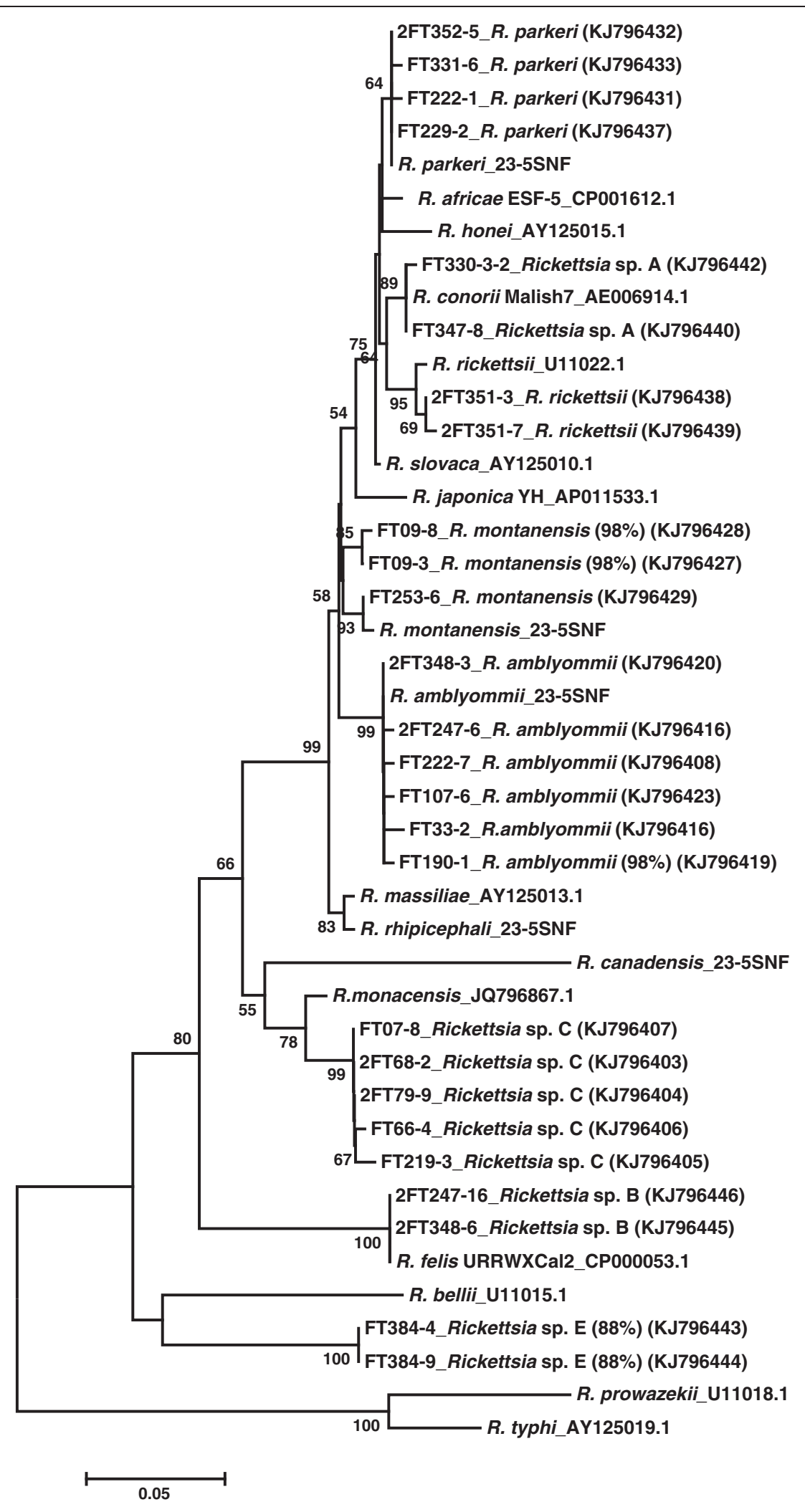

Figure 3 (See legend on next page.) 
(See figure on previous page.)

Figure 3 Neighbor-joining tree showing phylogenetic relationship of partial 23S-5S IGS sequences of known Rickettsia and species identified after cloning of tick genomic DNA samples that were initially classified as unknown and/or were identified as co-infected samples in RLB hybridization assays. Sequence homologies $<99 \%$ are indicated in parentheses after the sequence identity. The scale bar indicates an estimated change of 5\% 23S-5S IGS. Sequences beginning with "FT" or "2FT" were generated in this study. Bootstrap values below $50 \%$ are not shown in the tree branch. Accessions numbers for study samples are given in parentheses. *Unpublished GenBank sequences.

ticks positive for genus Rickettsia were also infected with E. chaffeensis $(n=5)$ or E. ewingii $(n=11)$. Two ticks containing E. chaffeensis contained multiple Rickettsia species (R. amblyommii $+R$. bellii and R. amblyommii $+R$. massiliae) based on RLB hybridization results. Two ticks containing E. ewingii contained $R$. parkeri or an unidentified Rickettsia species. In 2012, A americanum that carried $R$. amblyommii were also found to be positive for $E$. chaffeensis $(n=2)$, E. ewingii $(n=16)$, or A. phagocytophilum $(n=2)$. Two ticks infected with $E$. ewingii and $R$. amblyommii were also infected with Rickettsia sp. A or R. bellii. 23S-5S amplicons from two of three ticks infected with $E$. ewingii and an unidentified Rickettsia species were cloned and sequenced. These two A. americanum ticks were found to contain $R$. amblyommii and either Rickettsia sp. B or R. parkeri. The only co-infection which did not involve a Rickettsia species was detected in one A. americanum female, which was collected in 2012 and infected with $E$. chaffeensis and E. ewingii. All co-infections were detected in $A$. americanum except for one A. maculatum male (collected in 2011) that carried $R$. amblyommii, $R$. bellii and E. chaffeensis.

\section{Discussion}

\section{Comparative abundance of tick species}

Ticks collected by NC foresters, park service, and wildlife personnel from their skin were predominantly $A$. americanum with small numbers of $D$. variabilis, $I$. scapularis and $A$. maculatum. All four species have been reported to parasitize humans; however, within its geographic range, A. americanum generally dominated collections [34-38]. In northeastern states, I. scapularis was the most frequently collected tick [39], but this tick and A. maculatum have been infrequently collected from humans in southern states $[35,38,40]$.

\section{Rickettsia identified in ticks removed from the skin of outdoor workers}

Few comparable studies of the Rickettsiales pathogens contained in North American ticks removed from humans have been conducted. Our results indicate that outdoor workers in NC would experience the greatest risk of receiving ticks bites from A. americanum. Based on past studies $[16,18]$, we expected that $R$. amblyommii would be prevalent in the A. americanum tested. PCR-RLB hybridization provided a high throughput method for screening ticks for this and other Rickettsia species. In our investigation,
R. amblyommii accounted for $86.8 \%$ (416/479) of the Rickettsia species in $17-\mathrm{kDa}$-positive ticks removed from the skin of outdoor workers. Likewise, in past studies, $R$. amblyommii was the most frequently detected SFG Rickettsia in A. americanum and D. variabilis removed from the skin of people $[38,41,42]$. Similarly in other recent investigations of host-seeking ticks, $R$. amblyommii was the most prevalent species of Rickettsia detected in A. americanum $[16,18,43-48]$.

Because RLB hybridization probes used in our assay were $17-25 \mathrm{bp}$ in size, we anticipated some heterologous hybridizations would occur between $\sim 400$ bp 23S-5S amplicons and RLB probes. Accordingly, we cloned and sequenced 23S-5S gene fragments for some ticks containing Rickettsia species that failed to hybridize to any genus, group or species-specific probes or that gave unexpected hybridizations for particular tick species. RLB hybridization indicated that some ticks were co-infected but cloning and sequencing results indicated that only one tick contained two Rickettsia species. However, since only up to 5 clones per tick (1-2 clones for some ticks) were sequenced, it is likely that sequencing additional clones would have detected uncommon Rickettsia species. Albeit, cloning and sequencing of co-infected ticks identified Rickettsia species that were unexpected. Rickettsia species $C$, that was $98 \%$ homologous to $R$. monacensis for 23S-5S sequences, was detected in two A. americanum and three I. scapularis ticks. To our knowledge this Rickettsia species has not been detected in field-collected $A$. americanum or I. scapularis, but $R$. monacensis has been detected in I. ricinus in Europe [49,50]. However, our phylogenetic analyses showed that 23S-5S clone sequences clustered near GenBank $R$. monacensis sequences but on a separate branch, suggesting that the Rickettsia species might be a close relative of $R$. monacensis. Subsequent phylogenetic analyses of Rickettsia ompA and gltA sequences support this conclusion. Partial nucleotide sequences from several $A$. americanum clones clustered closely with $R$. conorii and $R$. rickettsii. $R$. conorii is the agent causing Mediterranean spotted fever and a variety of other rickettsioses in areas of Europe and Asia [51], so it is likely that the rickettsial species (Rickettsia sp. A) that we detected is a variant of $R$. conorii. $R$. rickettsii, the causal agent of Rocky Mountain spotted fever, has been identified previously in $A$. americanum [44,52]. Sequence matches for $R$. parkeri were obtained for clones from $6 A$. americanum and one $A$. maculatum. $R$. parkeri has been 
detected previously in A. americanum from Georgia and Tennessee [53] and Virginia [45]. This tick has been shown to be a competent laboratory vector for this rickettsial species [54]. $R$. parkeri is an established human pathogen [55] that is vectored by A. maculatum [56].

In addition to Rickettsia sp. A and C, ticks contained other novel Rickettsia spp. Classification of Rickettsia sp. $\mathrm{E}$ as a putative novel species is supported by phylogenetic analyses of $23 \mathrm{~S}-5 \mathrm{~S}$, ompA and gltA sequences. Rickettsia spp. B and D that are closely related to R. felis and $R$. typhi, respectively, are likely to be new species as well. Similarly, Heise et al. [43] detected novel Rickettsia sp. in $A$. americanum by amplifying, cloning and sequencing $17 \mathrm{kDa}$ and $g l t A$ genes.

\section{Other Rickettsiales organisms detected in ticks}

$E$. chaffeensis and $E$. ewingii are pathogens vectored by $A$. americanum [57] that cause human illness [58]. Stromdahl et al. [59] tested ticks removed from military personnel by PCR for common bacterial pathogens and reported finding $15 \%$ of $A$. americanum ticks containing a $16 \mathrm{~S}$ rRNA amplicon that matched the expected size of $E$. chaffeensis. Both pathogens have been reported in recently published molecular surveys of ticks [16-18,60-63]. Mean infection rates were geographically variable but generally similar to the rates that we observed (1.8\% for E. chaffeensis and $7.1 \%$ for $E$. ewingii). In previous studies, infection rates for $E$. chaffeensis ranged from a low of $2.0 \%$ for A. americanum in Georgia [61] to a high of $6.7 \%$ in Missouri [60]. In comparison, E. ewingii infection rates ranged from $0.8 \%$ for ticks in Tennessee [63] to 6.0\% for Mississippi [62].

An Ehrlichia species 99\% homologous (based on the $16 \mathrm{~S}$ rRNA gene target) to E. ruminantium was detected in A. americanum. Subsequent sequence analysis of glt $A$ gene fragments established that the tick was infected with the Panola Mountain Ehrlichia, a variant of E. ruminantium [31]. The Panola Mountain Ehrlichia is pathogenic to some domestic animals $[64,65]$ and humans $[66]$. This Ehrlichia species has not been reported to occur in $A$. americanum in North Carolina but has been detected in ticks collected in 3 other southern states [31].

\section{Conclusions}

In the southern U.S., illness from spotted fever rickettsioses, including Rocky Mountain spotted fever, has escalated markedly over the past decade while case fatalities have declined [67]. Concurrently, recent studies $[44,46,68,69]$ have failed to detect $R$. rickettsii in D. variabilis, an established vector of RMSF, which could account for the increased morbidity and decreased case fatality. Our results indicate that host-seeking A. americanum are infected with novel Rickettsia species. Further investigations are warranted to determine if these Rickettsia cause human illness. As suggested previously by Apperson et al. [17], these studies "...would include cell culture and molecular evaluation of human specimens from clinically ill patients to provide specific identity of the etiologic agent".

\section{Additional files}

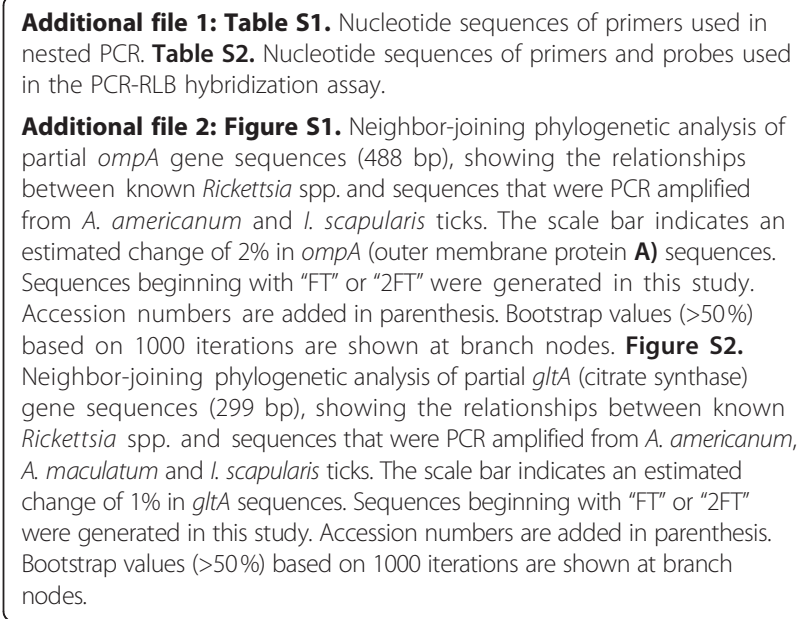

\section{Abbreviations}

SFR: Spotted Fever Rickettsioses; SFG: Spotted Fever Group; TG: Typhus Group; RMSF: Rocky Mountain spotted fever; RLB: Reverse-Line Blot.

\section{Competing interests}

The authors declare that they have no competing interests.

\section{Authors' contributions}

SL developed the PCR-reverse line blot (RLB) hybridization assay, analyzed ticks for Rickettsiales bacteria, and assisted with manuscript preparation. MK completed PCR-RLB hybridization assays, cloned and sequenced Rickettsia DNA and assisted with manuscript revision. LP directed laboratory work, analyzed experimental results, and assisted with manuscript revision. MV and SF coordinated the collection and shipment of ticks. HT extracted genomic DNA from ticks. SRM assisted with the interpretation of data and manuscript revision. CSA identified ticks, assisted with interpretation of data and, manuscript preparation and revision. All authors reviewed and approved the final version of the manuscript.

\section{Acknowledgements}

We are grateful to William L. Nicholson (Rickettisal Zoonoses Branch, CDC, Atlanta, GA, USA) for providing the Rickettsia species used in RLB hybridization assays. Our research was supported by a grant to SRM from the Centers for Disease Control and Prevention and the National Institute for Occupational Safety and Health (5R01OH009874).

\section{Author details}

'Department of Entomology, North Carolina State University, Campus Box 7647, Raleigh, NC 27695-7647, USA. ²Department of Epidemiology, Gillings School of Global Public Health, University of North Carolina, Chapel Hill, NC 27599, USA. ${ }^{3}$ Present address: National Institutes of Health, Bethesda, MD 20892, USA.

Received: 12 November 2014 Accepted: 16 December 2014 Published online: 23 December 2014

\section{References}

1. Parola P, Paddock CD, Raoult D: Tick-borne rickettsioses around the world: emerging diseases challenging old concepts. Clin Microbiol Rev 2005, 18:719-756

2. Renvoisé A, Mediannikov O, Raoult D: Old and new tick-borne rickettsioses. Intl Hth 2009, 1:17-25. 
3. Centers for Disease Control and Prevention: Summary of notifiable diseases-United States. MMWR 2013, 60:1-118.

4. Openshaw JJ, Swerdlow DL, Krebs JW, Holman RC, Mandel E, Harvey A, Haberling D, Massung RF, McQuiston JH: Rocky mountain spotted fever in the United States, 2000-2007: Interpreting contemporary increases in incidence. Am J Trop Med Hyg 2010, 83:174-182.

5. McCall CL, Curns AT, Rotz LD, Singleton JA Jr, Treadwell TA, Comer JA, Nicholson WL, Olson JG, Childs JE: Fort Chaffee revisited: the epidemiology of tick-borne rickettsial and ehrlichial diseases at a natural focus. Vector Borne Zoonot Dis 2001, 1:119-127.

6. Covert DJ, Langley RL: Infectious disease occurrence in forestry workers: a systematic review. J Agromed 2002, 8:95-111.

7. Piacentino J, Schwartz B: Occupational risk of Lyme disease: an epidemiological review. Occ Environ Med 2002, 59:75-84

8. Pages F, Dautel H, Duvallet G, Kahl O, de Gentile L, Boulanger N: Tick repellents for human use: prevention of tick bites and tick-borne diseases. Vector Borne Zoonot Dis 2014, 14:85-93.

9. Faulde M, Scharninghausen J, Tisch M: Preventive effect of permethrinimpregnated clothing to Ixodes ricinus ticks and associated Borrelia burgdorferi sl in Germany. Intl J Med Microbiol 2008, 298:321-324.

10. Vaughn MF, Meshnick SR: Pilot study assessing the effectiveness of long-lasting permethrin-impregnated clothing for the prevention of tick bites. Vector Borne Zoonot Dis 2011, 11:869-875.

11. Vaughn MF, Funkhouser SW, Lin F-C, Fine J, Juliano JJ, Apperson CS, Meshnick SR: Long-lasting permethrin impregnated uniforms: a randomized-controlled trial for tick bite prevention. Am J Prevent Med 2014, 46:473-480

12. Moreau CS, Wray BD, Czekanski-Moir JE, Rubin BE: DNA preservation: a test of commonly used preservatives for insects. Invert Systemat 2013, 27:81-86.

13. Ponnusamy L, Gonzalez A, Van Treuren W, Weiss S, Parobek CM, Juliano JJ, Knight R, Roe RM, Apperson CS, Meshnick SR: Diversity of Rickettsiales in the microbiome of the lone star tick, Amblyomma americanum. Appl Environ Microbiol 2014, 80:354-359.

14. Oliveira KA, Oliveira LS, Dias CCA, Silva A Jr, Almeida M, Almada G, Bouyer D, Galvão M, Mafra C: Molecular identification of Rickettsia felis in ticks and fleas from an endemic area for Brazilian Spotted Fever. Mem Inst Oswaldo Cruz 2008, 103:191-194.

15. Parola P, Paddock CD, Socolovschi C, Labruna MB, Mediannikov O, Kernif T, Abdad MY, Stenos J, Bitam I, Fournier P-E, Raoult D: Update on tick-borne rickettsioses around the world: a geographic approach. Clin Microbiol Rev 2013, 26:657-702.

16. Mixson TR, Campbell SR, Gill JS, Ginsberg HS, Reichard MV, Schulze TL, Dasch GA: Prevalence of Ehrlichia, Borrelia, and Rickettsial agents in Amblyomma americanum (Acari: Ixodidae) collected from nine states. J Med Entomol 2006, 43:1261-1268.

17. Apperson CS, Engber B, Nicholson WL, Mead DG, Engel J, Yabsley MJ, Dail K, Johnson J, Watson DW: Tick-borne diseases in North Carolina: is "Rickettsia amblyommii" a possible cause of rickettsiosis reported as Rocky Mountain spotted fever? Vector Borne Zoonot Dis 2008, 8:597-606.

18. Smith MP, Ponnusamy L, Jiang J, Ayyash LA, Richards AL, Apperson CS: Bacterial pathogens in ixodid ticks from a Piedmont County in North Carolina: prevalence of rickettsial organisms. Vector Borne Zoonot Dis 2010, 10:939-952.

19. Jado I, Escudero R, Gil H, Jimenez-Alonso MI, Sousa R, Garcia-Perez AL, Rodriguez-Vargas M, Lobo B, Anda P: Molecular method for identification of Rickettsia species in clinical and environmental samples. J Clin Microbiol 2006, 44:4572-4576.

20. Kong F, Gilbert GL: Multiplex PCR-based reverse line blot hybridization assay (mPCR/RLB)-a practical epidemiological and diagnostic tool. Nat Protoc 2006, 1:2668-2680.

21. Larkin MA, Blackshields G, Brown NP, Chenna R, McGettigan PA, McWilliam H, Valentin F, Wallace IM, Wilm A, Lopez R, Thompson JD, Gibson TJ, Higgins DG Clustal W and Clustal X version 2.0. Bioinformatics 2007, 23:2947-2948.

22. Choi Y-J, Jang W-J, Kim J-H, Ryu J-S, Lee S-H, Park K-H, Paik H-S, Koh Y-S, Choi M-S, Kim I-S: Spotted fever group and typhus group rickettsioses in humans, South Korea. Emerg Infect Dis 2005, 11:237-244.

23. Thompson JD, Gibson TJ, Plewniak F, Jeanmougin F, Higgins DG: The CLUSTAL_X windows interface: flexible strategies for multiple sequence alignment aided by quality analysis tools. Nucleic Acids Res 1997, 25:4876-4882.
24. Kumar S, Tamura K, Nei M: MEGA3: integrated software for molecular evolutionary genetics analysis and sequence alignment. Brief Bioinform 2004, 5:150-163.

25. Saitou N, Nei M: The neighbor-joining method: a new method for reconstructing phylogenetic trees. Mol Biol Evol 1987, 4:406-425.

26. Felsenstein J: Confidence limits on phylogenies: an approach using the bootstrap. Evolution 1985, 39:783-791.

27. Tamura K, Stecher G, Peterson D, Filipski A, Kumar S: MEGA6: molecular evolutionary genetics analysis version 6.0. Mol Biol Evol 2013, 30:2725-2729.

28. Buller RS, Arens M, Hmiel SP, Paddock CD, Sumner JW, Rikhisa Y, Unver A Gaudreault-Keener M, Manian FA, Liddell AM, Schmulewitz N, Storch GA: Ehrlichia ewingii, a newly recognized agent of human ehrlichiosis. N Engl J Med 1999, 341:148-155.

29. Sumner JW, Childs JE, Paddock CD: Molecular cloning and characterization of the Ehrlichia chaffeensis variable-length PCR target: an antigenexpressing gene that exhibits interstrain variation. J Clin Microbiol 1999, 37:1447-1453.

30. Nicholson WL, Castro MB, Kramer VL, Sumner JW, Childs JE: Dusky-footed wood rats (Neotoma fuscipes) as reservoirs of granulocytic ehrlichiae (Rickettsiales: Ehrlichieae) in northern California. J Clin Microbiol 1999, 37:3323-3327.

31. Loftis AD, Mixson TR, Stromdahl EY, Yabsley MJ, Garrison LE, Williamson PC, Fitak RR, Fuerst PA, Kelly DJ, Blount KW: Geographic distribution and genetic diversity of the Ehrlichia sp. from Panola Mountain in Amblyomma americanum. BMC Infect Dis 2008, 8:54.

32. Altschul SF, Gish W, Miller W, Myers EW, Lipman DJ: Basic local alignment search tool. J Mol Biol 1990, 215:403-410.

33. Cole JR, Wang Q, Cardenas E, Fish J, Chai B, Farris RJ, Kulam-Syed-Mohideen AS, McGarrell DM, Marsh T, Garrity GM, Tiedje JM: The Ribosomal Database Project: improved alignments and new tools for rRNA analysis. Nucleic Acids Res 2009, 37(Database issue):141-145.

34. Felz MW, Durden LA: Attachment sites of four tick species (Acari: Ixodidae) parasitizing humans in Georgia and South Carolina. J Med Entomol 1999, 36:361-364.

35. Merten HA, Durden LA: A state-by-state survey of ticks recorded from humans in the United States. J Vector Ecol 2000, 25:102-113.

36. Schulze TL, Jordan RA, Healy SP, Roegner VE, Meddis M, Jahn MB, Guthrie DL: Relative abundance and prevalence of selected Borrelia infections in Ixodes scapularis and Amblyomma americanum (Acari: Ixodidae) from publicly owned lands in Monmouth County, New Jersey. J Med Entomol 2006. 43:1269-1275

37. Murphree R, Hackwell N, Mead PS, Bachand A, Stromdahl EY: Prospective health assessment of Fort Campbell, Kentucky patrons bitten by ticks. Mil Med 2009, 174:419-425

38. Williamson PC, Billingsley PM, Teltow GJ, Seals JP, Turnbough MA, Atkinson SF: Borrelia, Ehrlichia, and Rickettsia spp. in ticks removed from persons, Texas, USA. Emerg Infect Dis 2010, 16:441-446.

39. Falco RC, Fish D: Ticks parasitizing humans in a Lyme disease endemic area of southern New York State. Am J Epidemiol 1988, 128:1146-1152.

40. Harrison B, Engber B, Apperson C: Ticks (Acari: Ixodida) uncommonly found biting humans in North Carolina. J Vector Ecol 1997, 22:6-12.

41. Billeter SA, Blanton HL, Little SE, Levy MG, Breitschwerdt EB: Detection of "Rickettsia amblyommii" in association with a tick bite rash. Vector Borne Zoonot Dis 2007, 7:607-610.

42. Jiang J, Yarina T, Miller MK, Stromdahl EY, Richards AL: Molecular detection of Rickettsia amblyommii in Amblyomma americanum parasitizing humans. Vector Borne Zoonot Dis 2010, 10:329-340.

43. Heise SR, Elshahed MS, Little SE: Bacterial diversity in Amblyomma americanum (Acari: Ixodidae) with a focus on members of the genus Rickettsia. J Med Entomol 2010, 47:258-268.

44. Berrada ZL, Goethert HK, Cunningham J, Telford SR: Rickettsia rickettsii (Rickettsiales: Rickettsiaceae) in Amblyomma americanum (Acari: Ixodidae) from Kansas. J Med Entomol 2011, 48:461-467.

45. Gaines DN, Operario DJ, Stroup S, Stromdahl E, Wright C, Gaff H, Broyhill J, Smith J, Norris DE, Henning T, Lucas A, Houpt E: Ehrlichia and spotted fever group rickettsiae surveillance in Amblyomma americanum in Virginia through use of a novel six-plex real-time PCR Assay. Vector Borne Zoonot Dis 2014, 14:307-316.

46. Nadolny RM, Wright CL, Sonenshine DE, Hynes WL, Gaff HD: Ticks and spotted fever group rickettsiae of southeastern Virginia. Ticks Tick Borne Dis 2014, 5:53-57. 
47. Zhang $X$, Ren $X$, Norris DE, Rasgon JL: Distribution and infection frequency of 'Candidatus Rickettsia amblyommii' in Maryland populations of the lone star tick (Amblyomma americanum) and culture in an Anopheles gambiae mosquito cell line. Ticks Tick Borne Dis 2012, 3:38-42.

48. Sayler K, Wamsley H, Pate M, Barbet A, Alleman A: Cultivation of Rickettsia amblyommii in tick cells, prevalence in Florida lone star ticks (Amblyomma americanum). Parasit Vectors 2014, 7:270.

49. Simser JA, Palmer AT, Fingerle V, Wilske B, Kurtti TJ, Munderloh UG: Rickettsia monacensis sp. nov., a spotted fever group Rickettsia, from ticks (Ixodes ricinus) collected in a European city park. Appl Environ Microbiol 2002, 68:4559-4566.

50. Rymaszewska A, Piotrowski M: Use of DNA sequences for Rickettsia identification in Ixodes ricinus ticks: the first detection of Rickettsia monacensis in Poland. Microbes Infect 2013, 15:140-146.

51. Macaluso K, Paddock CD: Tick-Borne Spotted Fever Group Rickettsioses and Rickettsia Species. In Biology of Ticks, Volume 2. 1st edition. Edited by Sonenshine DE, Roe RM. New York: Oxford University Press; 2014:211-250.

52. Breitschwerdt EB, Hegarty BC, Maggi RG, Lantos PM, Aslett DM, Bradley JM: Rickettsia rickettsii transmission by a lone star tick, North Carolina. Emerg Infect Dis 2011, 17:873-875.

53. Cohen SB, Yabsley MJ, Garrison LE, Freye JD, Dunlap BG, Dunn JR, Mead DG, Jones TF, Moncayo AC: Rickettsia parkeri in Amblyomma americanum ticks, Tennessee and Georgia, USA. Emerg Infect Dis 2009, 15:1471-1473.

54. Goddard J: Experimental infection of lone star ticks, Amblyomma americanum (L.), with Rickettsia parkeri and exposure of guinea pigs to the agent. J Med Entomol 2003, 40:686-689.

55. Paddock CD, Sumner JW, Comer JA, Zaki SR, Goldsmith CS, Goddard J, McLellan SL, Tamminga CL, Ohl CA: Rickettsia parkeri: a newly recognized cause of spotted fever rickettsiosis in the United States. Clin Infect Dis 2004, 38:805-811.

56. Jiang J, Stromdahl EY, Richards AL: Detection of Rickettsia parkeri and Candidatus Rickettsia andeanae in Amblyomma maculatum Gulf Coast ticks collected from humans in the United States. Vector Borne Zoonot Dis 2012, 12:175-182

57. Paddock CD, Yabsley MJ: Ecological havoc, the rise of white-tailed deer, and the emergence of Amblyomma americanum-associated zoonoses in the United States. CTMI 2007, 315:289-324.

58. Dumler JS, Madigan JE, Pusterla N, Bakken JS: Ehrlichioses in humans: epidemiology, clinical presentation, diagnosis, and treatment. Clin Infect Dis 2007, 45(Supplement 1):S45-S51.

59. Stromdahl E, Evans S, O'Brien J, Gutierrez A: Prevalence of infection in ticks submitted to the human tick test kit program of the US Army Center for Health Promotion and Preventive Medicine. J Med Entomol 2001, 38:67-74.

60. Steiert JG, Gilfoy F: Infection rates of Amblyomma americanum and Dermacentor variabilis by Ehrlichia chaffeensis and Ehrlichia ewingii in southwest Missouri. Vector Borne Zoonot Dis 2002, 2:53-60.

61. Varela AS, Moore VA, Little SE: Disease agents in Amblyomma americanum from northeastern Georgia. J Med Entomol 2004, 41:753-759.

62. Castellaw A, Showers J, Goddard J, Chenney E, Varela-Stokes A: Detection of vector-borne agents in lone star ticks, Amblyomma americanum (Acari: Ixodidae), from Mississippi. J Med Entomol 2010, 47:473-476.

63. Cohen SB, Yabsley MJ, Freye JD, Dunlap BG, Rowland ME, Huang J, Dunn JR, Jones TF, Moncayo AC: Prevalence of Ehrlichia chaffeensis and Ehrlichia ewingii in ticks from Tennessee. Vector Borne Zoonot Dis 2010, 10:435-440.

64. Loftis AD, Reeves WK, Spurlock JP, Mahan SM, Troughton DR, Dasch GA, Levin ML: Infection of a goat with a tick-transmitted Ehrlichia from Georgia, USA, that is closely related to Ehrlichia ruminantium. J Vector Ecol 2006, 31:213-223.

65. Qurollo BA, Davenport AC, Sherbert BM, Grindem CB, Birkenheuer AJ, Breitschwerdt EB: Infection with Panola Mountain Ehrlichia sp. in a dog with atypical lymphocytes and clonal T-cell expansion. J Vet Intern Med 2013, 27:1251-1255.

66. Reeves WK, Loftis AD, Nicholson WL, Czarkowski AG: The first report of human illness associated with the Panola Mountain Ehrlichia species: a case report. J Med Case Reports 2008, 2:139-141.

67. Centers for Disease Control and Prevention: Rocky Mountain Spotted Fever (RMSF). 2013: http://www.cdc.gov/rmsf/stats/.

68. Moncayo AC, Cohen SB, Fritzen CM, Huang E, Yabsley MJ, Freye JD, Dunlap BG, Huang J, Mead DG, Jones TF, Dunn JR: Absence of Rickettsia rickettsii and occurrence of other spotted fever group rickettsiae in ticks from Tennessee. Am J Trop Med Hyg 2010, 83:653-657.

69. Stromdahl EY, Jiang J, Vince M, Richards AL: Infrequency of Rickettsia rickettsii in Dermacentor variabilis removed from humans, with comments on the role of other human-biting ticks associated with spotted fever group rickettsiae in the United States. Vector Borne Zoonot Dis 2011, 11:969-977.

\section{Submit your next manuscript to BioMed Central and take full advantage of:}

- Convenient online submission

- Thorough peer review

- No space constraints or color figure charges

- Immediate publication on acceptance

- Inclusion in PubMed, CAS, Scopus and Google Scholar

- Research which is freely available for redistribution 